\title{
Design of Bacterial Foraging Interval Fuzzy Logic Controller on Hybrid Solar Tracker- Ocean Wave Energy Converter
}

\author{
Dwi Nur Fitriyanah ${ }^{1 *}$, Imam Abadi²
}

\begin{abstract}
The location of Indonesia which, is crossed by the equator, makes it rich in sunlight. Photovoltaic (PV) can convert solar energy into electrical energy. The Solar Tracker system can maximize the absorption of solar energy that enters the PV. The condition of the Indonesian archipelago also has the potential for ocean wave energy. The Hydrostatic transmission-based Wave Energy Converter system can convert ocean wave energy into electrical energy. This research combines two energies, namely solar energy and ocean waves. The importance of combining these two renewable energies is due to the non-continuous nature of solar energy, therefore combined with the ocean wave energy to maximize the energy produced. A type-2 fuzzy logic control system based on Bacterial Foraging Optimization (BFO) is applied to each converter, summing each converter that has been optimizing. Optimize error and delta error on the solar tracker system and fuzzy logic waveform-based sea-wave type-2 system. The fuzzy boundaries are then optimized using the BFO optimization method. Fuzzy type-2 based on BFO in solar tracking system can increase energy by $67.9 \%$ with the best performance at FOU \pm 0.1 . BFObased type- 2 fuzzy control can stabilize the output of the ocean wave conversion system and produce average energy of 34.48 Wh. This research can increase the energy in the system after being optimized using BFO by $19.3 \%$.
\end{abstract}

Keywords - Bacterial foraging optimization, Electrical energy, Ocean wave energy, Solar energy, Type-2 fuzzy logic

\section{INTRODUCTION}

$I^{\prime}$ ndonesia is a tropical country that is crossed by the equator. The intensity of sunlight every day is high so that Indonesia has a huge potential in terms of utilizing renewable energy sources. One of the renewable energy considered in Indonesia is solar energy. It can be seen exposure to the sun in the west are exposed to solar energy of about 4.5 to $4.8 \mathrm{kWh} / \mathrm{m}^{2} /$ day with a monthly deviation of $10 \%$. East region have exposure to solar energy up to $5.1 \mathrm{kWh} / \mathrm{m}^{2} /$ day with a monthly deviation of about $9 \%$ [1]. Renewable energy grows with a growth rate of $6.8 \%$ per year for the basic scenario and $7.5 \%$ for the high scenario until 2050. Renewable energy sources solar power in Indonesia amounted to $4.80 \mathrm{kWh} / \mathrm{m}^{2} /$ day [2]. This solar power can convert into electrical energy, one of which is by using photovoltaic.

The research of the solar tracker system with one-axis has been carried out by Abadi et al in 2014 [3]. The weakness of this system lies in the accuracy in tracking the position of the sun because it only uses one axis. A year later Abadi et al researched solar tracker system with twoaxes. This research can improve the deficiencies of previous research, namely a one-axis solar tracker system. Some artificial intelligent control methods have applied to the solar tracker system such as fuzzy, fuzzy PSO, fuzzy type-2, etc [4], [5], [14], [15], [6]-[13]. In 2015, Abadi et al could increase efficiency by $50-60 \%$ using fuzzy control based PSO (Particle Swarm Optimization) optimization methods on a two-axis solar tracker system [16]. The performance produced by solar tracker increases after being optimized using PSO. The two-axis solar tracking system that uses fuzzy type-2 logic has better performance than type 1 fuzzy logic [15], [17].

\footnotetext{
Departement of Instrumentation Engineering, Institut Teknologi Sepuluh Nopember (ITS), Surabaya, Indonesia. E-mail: dwinur.fitriyanah@gmail.com
}

In 2012, Aghajarian et al proposed the use of fuzzy logic-Bacterial Foraging Optimization (BFO) in robot manipulators [18]. This research resulted in better accuracy response than fuzzy-PSO. BFO an algorithm inspired by the strategy of E.coli bacteria in searching for food, this theory has been successfully implemented in several technical issues. BFO is a combination of chemotaxis, swarming, reproduction, elimination, and dispersal processes. Each bacterium contains two parameters namely the altitude and azimuth angle of the sun to be verified with PV angles to obtain increased efficiency.

Intelligent control methods can also applied to ocean wave energy conversion. Research about wave energy conversion has been carried out by Ahn et al in 2012 [19]. This research can absorb $65 \%$ of energy using fuzzy control. Two years later Truong and Ahn conducted a study using a combination of fuzzy control and PID [20]. This study was able to correct the shortcomings of previous studies that can increase energy absorption by $78 \%$. Development of ocean wave energy conversion at this time is more developed towards the structure or modeling of the conversion itself. In this study, the author tries to develop fuzzy control on ocean wave energy conversion systems using BFO optimization.

The electricity generated can be also optimized by combining the two renewable energies above, combining solar tracker and OWEC. The combination of OWEC and PV has been done in Malaysia by Samrat et al [21]. The weakness of this research is still used PI control in Photovoltaic. There is no control in the OWEC system.

Some of the research above shows that solar tracker has better performance when using a two-axis solar tracker with type- 2 fuzzy control and optimization methods. The

\footnotetext{
2 Department of Engineering Physics, Institut Teknologi Sepuluh Nopember (ITS), Surabaya, Indonesia. $\quad$ E-mail: imamabadi02@gmail.com
} 
BFO optimization method chosen because the research conducted by Aghajarian et al showed that fuzzy-BFO was superior to fuzzy-PSO in terms of response accuracy [18]. OWEC and solar tracker systems use BFO-based type 2 fuzzy controls. The developed BFO type-2 fuzzy control mechanism was developed by modifying the type-2 fuzzy membership function model by determining the boundaries of the type-2 fuzzy input membership function that was updated based on an objective function namely Mean Square Error (MSE). The combination of two energies is expected to be able to increase the energy produced and meet the electricity needs. In the future, it is also expected that it can support the energy needs at the coast or offshore.

\section{METHOD}

\section{A. Solar Tracker System}

The solar tracker functions to guide the photovoltaic (PV) direction of the coming of the sun. PV that not aligned with the direction of the sun's coming causes the intensity of sunlight received by the PV is not the same (not optimal). Therefore, a controller is needed to track the position of the sun. The two-axis solar tracker system aims to control the pitch and yaw angle of the PV based on the azimuth and the altitude angle.

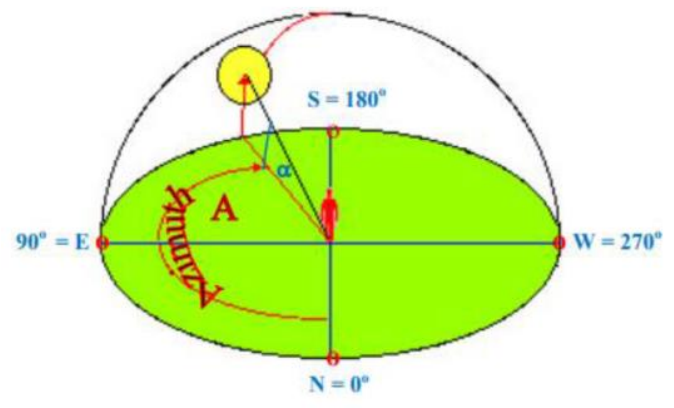

Figure 1. Position of The Sun [22]

The solar tracker system uses two DC motors that function to move the solar panel in the direction of pitch and yaw. The DC motor used is a $12 \mathrm{~V}$ DC motor. Data retrieval is done by providing input in the form of a voltage from 2-12 Volts. After that, the motor rpm value will be obtained.

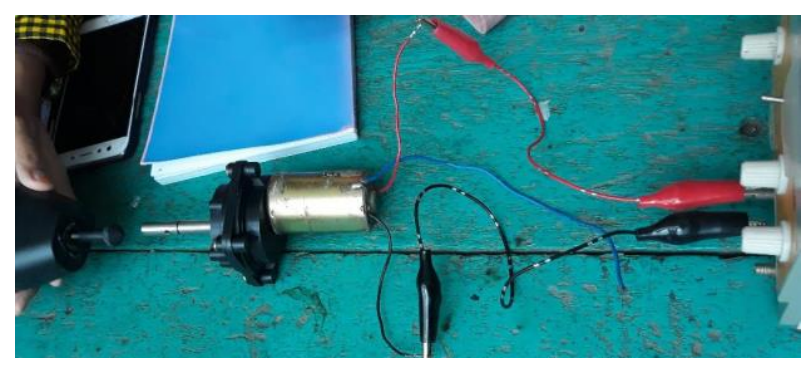

Figure 2. 12V DC Motor

There are two solar tracking inputs, namely radiation and temperature in the BFIT2FLC design. These two components change with time. Therefore, a controller is needed so that the input that enters the solar tracker is controlled following changes in the altitude and azimuth angle which change with time. The block diagram of the solar tracker system can explain in Figure 3.

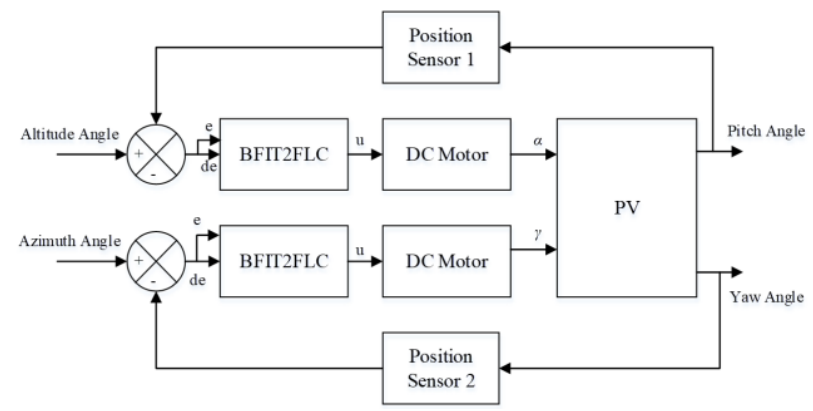

Figure 3. Block Diagram of Solar Tracker

The BFO type-1 fuzzy membership function changed to the type-2 BFO fuzzy is an input membership function at the pitch angle and yaw angle. Figure 4 is the membership function at the output and rule base used for the controller is the same, whether it is fuzzy type-1, fuzzy type-1 BFO, or fuzzy type-2 BFO.

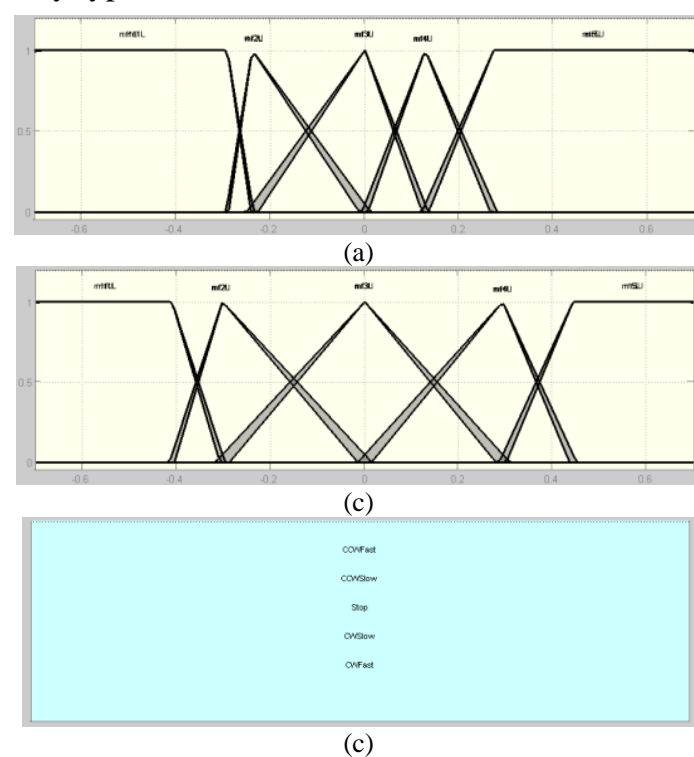

Figure 4. BFIT2FLC Membership Function Input (a) Pitch Angle, (b) Yaw Angle, and (c) Output of Solar Tracker

TABLE 1.

RULE BASE OF FUZZY CONTROL ON SOLAR TRACKER SYSTEM

\begin{tabular}{cccccc}
\hline$\Delta e$ & $\mathrm{NB}$ & $\mathrm{NS}$ & $\mathrm{ZE}$ & $\mathrm{PS}$ & $\mathrm{PB}$ \\
\hline $\mathrm{NB}$ & $\mathrm{CCWF}$ & $\mathrm{CCWF}$ & $\mathrm{CCWS}$ & $\mathrm{CCWS}$ & $\mathrm{S}$ \\
$\mathrm{NS}$ & $\mathrm{CCWF}$ & $\mathrm{CCWS}$ & $\mathrm{CCWS}$ & $\mathrm{S}$ & $\mathrm{CWS}$ \\
$\mathrm{ZE}$ & $\mathrm{CCWS}$ & $\mathrm{CCWS}$ & $\mathrm{S}$ & $\mathrm{CWS}$ & $\mathrm{CWS}$ \\
$\mathrm{PS}$ & $\mathrm{CCWS}$ & $\mathrm{S}$ & $\mathrm{CWS}$ & $\mathrm{CWS}$ & $\mathrm{CWF}$ \\
$\mathrm{PB}$ & $\mathrm{S}$ & $\mathrm{CWS}$ & $\mathrm{CWS}$ & $\mathrm{CWF}$ & $\mathrm{CWF}$ \\
\hline
\end{tabular}

where,

NB: Negative Big CCWF: Counter Clockwise Fast

NS: Negative Small CCWS: Counter Clockwise Slow

ZE: Zero S: stop 


\section{PS: Positive Small CWF: Clockwise Fast \\ PB: Positive Big \\ CWS: Clockwise Slow}

\section{B. OWEC System}

OWEC system is a system that converts ocean wave energy to electricity. There are three basic systems for converting ocean wave energy, namely the canal system, the buoy system, and the pool oscillation system. The buoy system is a system for generating electricity by moving the hydraulic pump from vertical and rotational movements of the buoy. The HSTWEC-based buoy system is the principal design of the system that proposed to convert ocean wave potential energy into electrical energy. The up and down motion of the buoy that connected to the pulley causes movement in the hydraulic pump so that the pulley speed is as speed as the hydraulic pump speed.

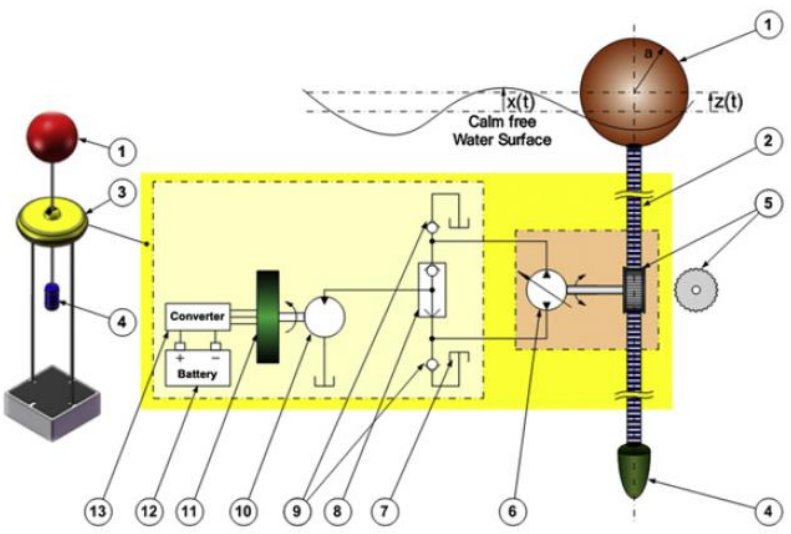

Figure 5. Structure on HSTWEC [19]

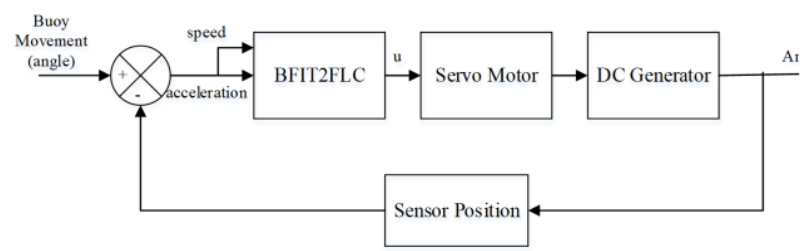

Figure 4. Block Diagram of OWEC

The design of OWEC systems uses the buoy connected via pulleys. The movement of the buoy causes the pulley to move and rotate according to the status of the wave. Pulley movement can move the piston so that it can produce motion that can rotate the motor and generator to produce electrical energy. An unstable pulley output connected to the pump affects the power output. The speed of the pump that drives the electric motor is controlled by BFIT2FLC.

The stages of BFIT2FLC control design are the same as the solar tracker system. The difference lies in the design of the membership function design and the rules used. Fuzzy input of solar tracker in the form of error and delta error, while fuzzy input of OWEC in the form of pump speed and acceleration. The membership functions of fuzzy, fuzzy-BFO, and fuzzy Type-2 controls in other energy conversion systems can see Figure 5.

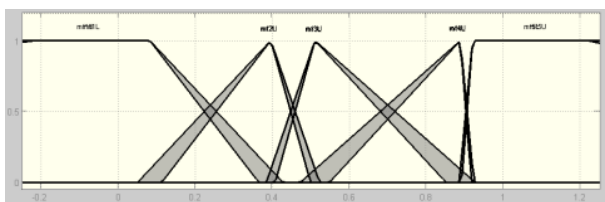

(a)

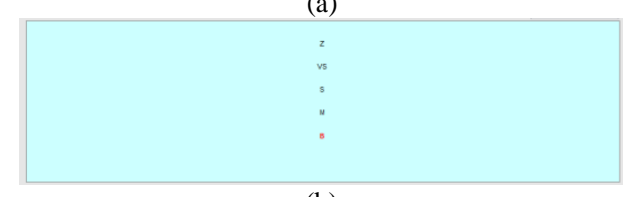

(b)

Figure 5. BFIT2FLC Membership Function (a) Input and (b) Output of OWEC

TABLE 2.

RULE BASE OF FUZZY CONTROL ON OWEC SYSTEM

\begin{tabular}{cccccc}
\hline $\mathrm{Z}$ & $\mathrm{Z}$ & $\mathrm{VS}$ & $\mathrm{S}$ & $\mathrm{M}$ & $\mathrm{B}$ \\
$\mathrm{VS}$ & $\mathrm{Z}$ & $\mathrm{M}$ & $\mathrm{B}$ & $\mathrm{B}$ & $\mathrm{S}$ \\
$\mathrm{S}$ & $\mathrm{Z}$ & $\mathrm{M}$ & $\mathrm{M}$ & $\mathrm{B}$ & $\mathrm{M}$ \\
$\mathrm{M}$ & $\mathrm{VS}$ & $\mathrm{S}$ & $\mathrm{S}$ & $\mathrm{S}$ & $\mathrm{M}$ \\
$\mathrm{B}$ & $\mathrm{Z}$ & $\mathrm{ZS}$ & $\mathrm{VS}$ & $\mathrm{B}$ \\
\hline \hline
\end{tabular}

where,

Z: zero $\quad$ M: medium

VS: very small B: big

S: small

\section{Method of Bacterial Foraging Optimization} Algorithm (BFOA)

Bacterial Foraging Optimization Algorithm belongs to the category of bacterial optimization algorithms and swarms optimization, this algorithm inspired by the foraging behavior of bacteria such as E.coli and M.xanthus [23]. Bacteria will move toward/away from certain signals. The strategy of foraging bacteria consists of 4 processes, namely chemotaxis, reproduction, elimination, and swarm [24]. BFO and PSO algorithms can overcome the problem of accuracy and make changes so that we can achieve the goal by reducing the value (cost) and increasing efficiency.

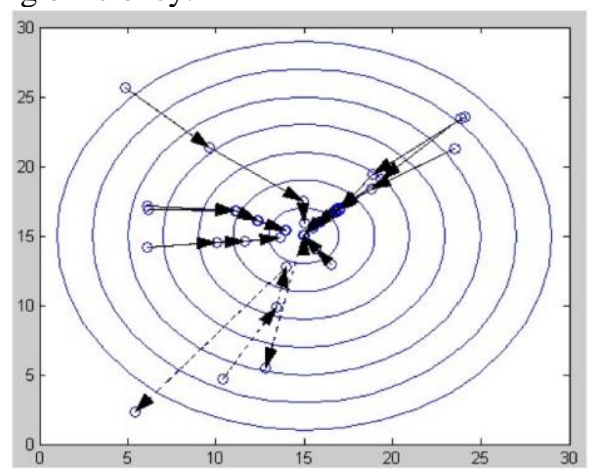

Figure 6. Bacteria Trajectory

Abadi et al. in 2019 have reported a PSO based fuzzy on a two-axis solar tracker system [6]. Besides being able to be used on MPPT (Maximum Power Point Tracking) [5], PSO based fuzzy controls can be also applied to solar tracker systems (without MPPT). The BFO algorithm is superior to the PSO algorithm in terms of response accuracy [18]. In 2018, Fitriyanah et al. researched solar tracker using BFO based fuzzy control [25]. The study 
resulted in higher performance when using fuzzy controls based on BFO rather than using fuzzy controls alone. Based on previous studies, this study uses BFIT2FLC that is applied to the solar tracker system and OWEC to improve the performance of the system.

The process of chemotaxis achieved by swimming and tumbling. When bacteria meet a good environment, then they will continue to swim in the same direction. Meanwhile, if bacteria meet an unfavorable environment, the bacteria will tumble or change direction.

$$
\theta^{i}(j+1, k, l)=\theta^{i}(j, k, l)+C(i) \Phi(j)
$$

The process of reproduction, in which bacteria are in good condition during their lives that can contribute to the next generation.

$$
J^{i} \text { health }=\sum_{j=1}^{N c} P^{i, j, k, l}
$$

where,

$\mathrm{C}(\mathrm{i})$ :the measure of the step taken determines the direction at random.

$\Phi(\mathrm{j})$ : in the random direction determined by the tumble.

$\mathrm{Nc}$ :The total number of steps of the complete chemotaxis process.

An elimination process occurs, where the bad bacteria will be removed, and a new random sample will be introduced with a low probability. The swarming process is any moving bacteria can give a signal to other bacteria to swarm towards it. BFO simulates such behavior by combining cell-to-cell attraction and repelling effects.

\section{RESUlTS AND DISCUSSION}

In Figure 7 show the output power generated by the solar tracker and fixed PV. The maximum power generated in fixed PV is 166.86 Watt while in the solar tracker is 244.37 Watt. The maximum output occurs at 240 minutes or at 11:00 WIB, where the highest irradiation (peak value) occurs at 11.00 WIB on 27 April 2019. Solar tracker can track the sun and absorb energy optimally compared to fixed PV. Evidenced by the energy output of the solar tracker is greater than the fixed PV. The fixed PV generate total energy as big as 1010.5 Watt-hours (Wh) for 10 hours or 600 minutes. The total energy produced by the PV tracker is $1696.8 \mathrm{~W} \mathrm{~h}$ for 10 hours or 600 minutes. Increased energy efficiency generated by the solar tracker system using BFIT2FLC is $67.9 \%$ over fixed PV.

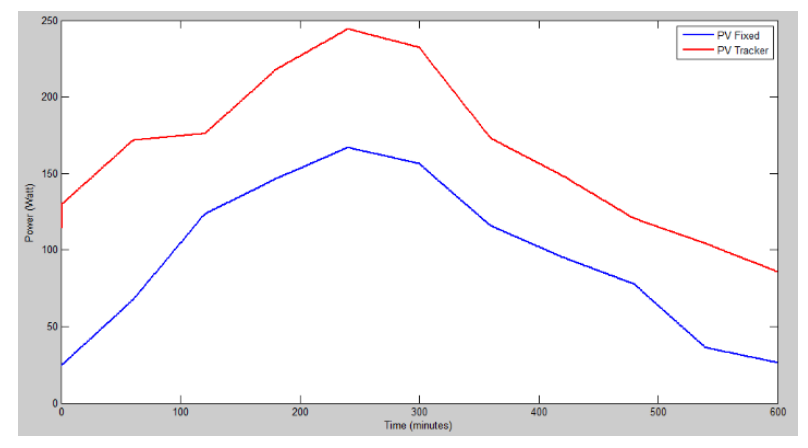

Figure 7. Power Comparison between PV Fixed and Solar Tracker

Figure 8 is the power output generated by the OWEC system. The system is relatively stable when controlled using BFIT2FLC FOU \pm 0.1 . BFIT2FLC control functions so that the pump output speed is stable with the input in the form of a sine wave status. There is fluctuation at the start of producing power. The new power output is stable in the $133^{\text {rd }}$ minute. There are fluctuations in the initial start caused by several things that are the generator type and the rotation that occurs in the generator. Pulley output entering the pump after being controlled using the BFIT2FLC control results in a stable speed. The pulley output then entered into the pump model, and motor resulting in a motor speed which fluctuates at the initial start. The power produced every hour is almost the same, which is around $34.48 \mathrm{Wh}$.

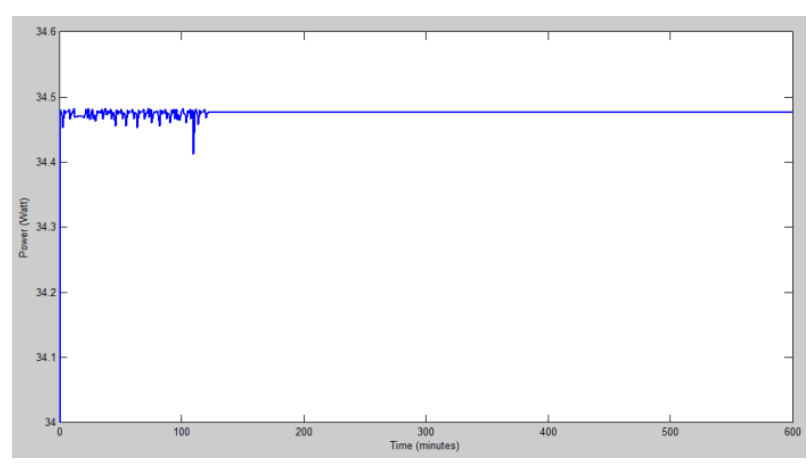

Figure 8. Power Generated on OWEC

Figure 9 is a comparison of the cumulative energy produced by the solar tracker and OWEC every hour. The total cumulative energy produced by the hybrid system is 2132.2 Wh. Based on the energy produced by each solar tracker system and OWEC, there is an average energy increase of $19.3 \%$ after summing the output of the solar tracker system. The increase in energy that produced is taken from energy every hour in each system and summing circuit.

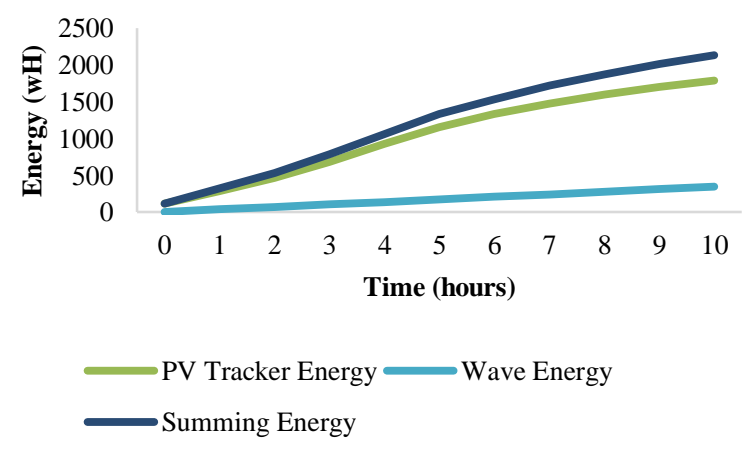

Figure 9. Comparison of Cumulative Energy Summing between Solar Tracker and OWEC

\section{CONCLUSION}

Fuzzy type-2 BFO on the solar tracking system can increase energy by $67.9 \%$ with the best performance on FOU \pm 0.1 . Fuzzy type- 2 BFO control can stabilize the output of the ocean wave conversion system and produce average energy of $34.48 \mathrm{Wh}$. There was an increase in energy average by $19.3 \%$ after the summing process between solar tracker system and ocean wave energy converter. A converter circuit is required if the summing output inserted into the battery. 


\section{REFERENCES}

[1] A. J. Veldhuis and A. H. M. E. Reinders, "Reviewing the potential and cost-effectiveness of off-grid PV systems in Indonesia on a provincial level," Renew. Sustain. Energy Rev., vol. 52, pp. 757-769, 2015.

[2] I. Fitriana, Anindhita, A. Sugiyono, L. M. A. Wahid, and Adiarso, Outlook Energi Indonesia 2017. Jakarta: Pusat Teknologi Sumber Daya Energi dan Industri Kimia (PTSEIK); Badan Pengkajian dan Penerapan Teknologi (BPPT), 2017.

[3] I. Abadi, A. Musyafa, and A. Soeprijanto, "Design of Single Axis Solar Tracking System at Photovoltaic Panel Using Fuzzy Logic Controller," 5th Brunei Int. Conf. Eng. Technol. (BICET 2014), no. NOVEMBER 2014, p. 2.04 (6 .)-2.04 (6 .), 2014.

[4] I. Abadi, E. H. Setyawan, and M. Ardiansyah, "Design of Automatic Switching System and Data Acquisition on Mobile Hybrid Solar Tracking System for Stand Alone Small PV with Reflector," IOP Conf. Ser. Earth Environ. Sci., vol. 520, no. 1, 2020 .

[5] I. Abadi, D. Nur Fitriyanah, and A. U1 Umam, "Design of Maximum Power Point Tracking (MPPT) on Two Axes Solar Tracker Based on Particle Swarm Fuzzy," in AIP Conference Proceedings, 2019, vol. 2088, p. 20041.

[6] I. Abadi, A. Musyafa, K. D. Baskoro, and D. N. Fitriyanah, "Design and Implementation of Mobile Active Two-Axis Solar Tracker with Reflector Based on Particle Swarm Fuzzy Controller," vol. 12, no. April, pp. 113-122, 2019.

[7] I. Abadi, C. Imron, M. Musa Bachrowi, and D. Nur Fitriyanah, "Design and implementation of battery charging system on solar tracker based stand alone PV using fuzzy modified particle swarm optimization," AIMS Energy, vol. 8, no. 1, pp. 142-155, 2020 .

[8] I. Abadi, D. N. Fitriyanah, and A. U. Umam, "Design of maximum power point tracking (MPPT) on two axes solar tracker based on particle swarm fuzzy," in AIP Conference Proceedings, 2019, pp. 1-10.

[9] I. Abadi, C. Imran, and N. Fasa, "Smart Solar Tracking System Based on Fuzzy-PI Controller for Maximizing The Power of PV," AIP Conf. Proc., vol. 2088, no. March, 2019.

[10] E. H. Setyawan, I. Abadi, and S. A. Kusumawarni, "Estimation of Hourly Solar Radiation on Horizontal Surface Using GAMF (Genetic Algorithm Modified Fuzzy) (Case Study in Surabaya)," IOP Conf. Ser. Mater. Sci. Eng., vol. 588, no. 1, 2019.

[11] A. Kurniawan and I. Abadi, “Analysis green gases reduction for employee buses in order to support fossil fuel conversion to electric powered buses in Pt. Vale Indonesia TBk," AIP Conf. Proc., vol. 2088, 2019.

[12] A. Musyafa, I. Abadi, R. D. Noriyati, R. I. Mukromin, T. A. Rafi, and M. K. Asy'ari, "Design and Implementation Monitoring System Based Internet Of Tings (IoT) on Battery Charging - Photovoltaic Power Plant Using FLC," Int. J. Mech.
Mechatronics Eng. IJMME-IJENS, vol. 20, no. 04, pp. 22-30, 2020.

[13] C. Imron, I. Abadi, I. Amirul Akbar, J. Maknunah, Y. Ahmad Nor, and A. Saepul Uyun, "Performance Comparison of the Single Axis and Two-Axis Solar System using Adaptive NeuroFuzzy Inference System Controls," E3S Web Conf., vol. 190, pp. 1-11, 2020.

[14] I. Abadi, T. Oktavia Hardiana, C. Imron, D. Nur Fitriyanah, Y. Jani, and K. Abdullah, "Design of Adaptive Neuro-Fuzzy Inference Control Based One-Axis Solar Tracker on Battery Charging System," E3S Web Conf., vol. 190, 2020.

[15] I. Abadi, Q. Uyuniyah, D. Nur Fitriyanah, Y. Jani, and K. Abdullah, "Performance Study of Maximum Power Point Tracking (MPPT) Based on Type-2 Fuzzy Logic Controller on Active Dual Axis Solar Tracker," E3S Web Conf., vol. 190, pp. 1-16, 2020.

[16] I. Abadi, A. Musyafa, and A. Soeprijanto, "Design and Implementation of Active Two Axes Solar Tracking System Using Particle Swarm Optimization Based Fuzzy Logic Controller," Int. Rev. Model. Simulations, vol. 8, no. 6, pp. 640652, 2015.

[17] I. Abadi, A. Musyafa', and A. Soeprijanto, “Type-2 Fuzzy Logic Controller Based PV Passive Two-Axis Solar Tracking System," Int. Rev. Electr. Eng., vol. 10, no. 3, 2015.

[18] M. Aghajarian, "Design of Fuzzy Controller for Robot Manipulators Using Bacterial Foraging Optimization Algorithm," J. Intell. Learn. Syst. Appl., vol. 04, no. 01, pp. 53$58,2012$.

[19] K. K. Ahn, D. Q. Truong, H. H. Tien, and J. Il Yoon, “An innovative design of wave energy converter," Renew. Energy, vol. 42, pp. 186-194, 2012.

[20] D. Q. Truong and K. K. Ahn, "Development of a novel point absorber in heave for wave energy conversion," Renew. Energy, vol. 65, pp. 183-191, 2014.

[21] N. H. Samrat, N. Bin Ahmad, I. A. Choudhury, and Z. Bin Taha, "Modeling, control, and simulation of battery storage photovoltaic-wave energy hybrid renewable power generation systems for island electrification in malaysia," Sci. World J., vol. 2014, no. July, 2014.

[22] D. Maslanka, "Solar Geometry," in Lecture handout: Applied Mathematics, Illinois Institute of Technology, Illinois., 2000.

[23] J. Brownlee, Clever Algorithms. 2011.

[24] J. Li, "Analysis and Improvement of the Bacterial Foraging Optimization Algorithm," J. Comput. Sci. Eng., vol. 8, no. 1, pp. 1-10, 2014.

[25] D. Nur Fitriyanah and I. Abadi, "Fuzzy Logic Control Design of Mobile PV Using Bacterial Foraging Optimization," 2018, pp. 215-220. 